consumers as to the level of endorsement and support from the ICO. Schemes will need to have triggers for ad hoc audits and have an 'appropriate level' of regular audit and review as part of this practice. Determining what that 'appropriate level' will be is the challenge, and it is important that industry and consumers participate in this debate with the ICO and provide feedback to ensure that any ICO endorsement of a seal scheme really does have value.

\title{
Big VAT changes for B2C supply of e-services in the EU
}

\section{Mark Brailsford}

Journal of Direct, Data and Digital Marketing Practice (2014) 16, 144-145. doi:10.1057/dddmp.2014.73

Who: HMRC (and equivalent bodies in other European Union states) Where: EU-wide

When: 1 January 2015

\section{Change to place of supply rule}

\footnotetext{
Impact on pricing in ads
}

\section{What happened}

As of 1 January 2015, changes to the VAT 'place of supply' rules will take effect across the EU for certain digital services, such as broadcasting, telecommunication and e-services, for example, music downloads, apps and video on demand. Currently, sales to consumers (or, in VAT terms, non-business customers) are subject to VAT where the selling business is based. The new rules will change the position so that all such supplies are subject to VAT where the customer is based. This means that businesses will be required to identify where each of their consumer customers is based and then account for VAT at the rates applicable for each such EU country. (They will need to do this either by registering for VAT in each such country or by using a new concept of a 'mini one-stop shop', or a 'MOSS' in the jargon, to register for VAT in one relevant country and account for all VAT payable across the EU through this one registration.)

\section{Why this matters}

Businesses will need to have systems in place to identify the location of their customers and enable them to charge the correct rate of VAT. This will be harder in some cases than in others. From an advertising and marketing perspective, the impact will be on the advertising of pricing. In a scenario where offers of e-services are made cross border and there is 
How to determine pricing uncertainty as to which EU state a potential purchaser may be located in, and thus which VAT rate may apply, how should the pricing be advertised? If the thought processes move towards VAT-exclusive pricing, both the Consumer Protection from Unfair Trading Regulations 2008 and the Consumer Contracts (Information, Cancellation and Additional Charges) Regulations 2013, which implement EU Directives saying the same thing, only allow the quoting of VAT-exclusive prices where "the nature of the goods or services is such that the price cannot reasonably be calculated in advance [in which case] the manner in which the price is calculated [must be stated]'.

Can it be argued that, because the new 'location of the consumer' rule applies only to services of a particular nature, the "nature of the goods or services' saving applies and a VAT-exclusive price can be quoted, provided the manner in which the tax will be calculated is explained? Alternatively, would it suffice to link all price indications to a chart showing the VAT-inclusive price in all EU states to which sales may be made? EU e-suppliers will no doubt be grappling with these questions over the next few weeks.

Mark Brailsford, consultant, Osborne Clarke, London 